\title{
Enhancing students' learning with Game-Based Approaches
}

\author{
Kwan Yuet Ling, Linda \\ The Education University of Hong Kong \\ ylkwan@eduhk.hk
}

\begin{abstract}
This study arises out of research in a school where the majority of students, aged between seven and nine, had experienced substantial difficulty in problem-solving in mathematics. The study was designed to discover why such a large body of students had so many difficulties in solving what, to their peers elsewhere, might be seen as simple arithmetic problems well within their capabilities. The study was designed to discover the extent of the students' difficulties and the reasons for them. 27 students were studied over a period of many months. Each was interviewed face-to-face. Of the 27 students, four were then selected for further in-depth interviews. All interviews were videotaped and the recordings were studied and analysed and relevant data extracted. The findings disclosed a number of problems on math language in both procedural and conceptual knowledge, the details of which, it was felt, could help the teachers understand the symptoms of the poor performance and the reasons for it so that they could then design a suitable remedial programme. Gamebased approaches were used to enhance students' learning.
\end{abstract}

Keywords: conceptual; knowledge; procedural; solving problems; game-based approaches

\section{INTRODUCTION}

Internationally, early number skills are an important part of both policy documents and research into early mathematics (Kilpatrick, Swaford, and Findell 2001). Young children encounter counting and addition before they enter formal schooling and this provides a foundation for learning mathematics. They tend to encounter these skills well before kindergarten and the importance of mastering the skills at as early an age as possible cannot be over-emphasized. The ability to count and add numbers gives children a framework for learning mathematics, initially in kindergarten and, subsequently in primary or elementary school. The current study aimed to investigate how students aged between seven and nine years solved arithmetic addition problems. The research question will be investigated: What solution strategies do students use to solve arithmetic addition problems by game-based approaches? 
The children were presented with simple arithmetic problems with 'guessing game' (Neuman, 1987). Unlike simple addition and missing addend problems, the guessing game problem is not one which one would expect most students to have encountered in their day-to-day lives, but what the problem does do is give teachers a real insight into the level of understanding achieved by their student's in their learning of simpler arithmetic problems.

Because the guessing game does not represent a familiar situation to students it is necessary for them to stand back and ask how they can make sense of the problem. Can they, for example, see this as a missing addend problem or try to solve it as a subtraction problem. As the study shows, once the students were able to look to their experience of simple addition, missing addend and subtraction problems, the guessing game became easy. That's the beauty of the guessing game - it really makes the student think and build a bridge between their previous experience and the novel experience that the guessing game presents and is serves as a highly effective diagnostic tool for the teacher.

\section{LITERATURE REVIEW}

Many scholars and authority have defined the term "game." Bernard Spodek and Olivia Saracho proved that games constitute a separate type of play activity. They are very wellstructured and have certain regulations that must be obeyed. Games, according to Jill Hadfield, are "an activity with rules, a goal and an element of fun." Games were defined by Byrne as "a type of play regulated by rules." They should be enjoyable and enjoyable. They are not only a fun diversion from everyday activities, but also a means to get the learner to utilize the language throughout the game.

It is well understood that motivation is influenced by a variety of factors, one of which is interest. The use of a game-based method in elementary school mathematics classes makes kids happy. It has the potential to pique students' curiosity for information, causing them to take an interest in what they are studying in class; interest, in turn, can lead to academic achievement. Finally, students' motivation to learn Mathematics is fueled by their desire to succeed. Children's finest teacher is their own interest.

For younger children, in particular, counting is of fundamental importance in their understanding of mathematics ("Counting and Young Children," n.d.). Counting is at the very root of understanding mathematics. This means that, if a child is to progress in mathematics, they must have the fullest range of counting strategies and understand how to use them. In the study, particular attention was paid to the counting strategies employed by the students, which strategies they chose to solve a particular problem (and why) and how they performed in using a particular strategy. Counting has been the subject of much research and the findings of earlier researchers were most instructive and were borne in mind during the study (Gibbons \& Lomax, 2015). 


\section{Counting strategy}

'Counting is a process in which the objects in a set are noted one at a time, each object being noted once and only once. Further, as each object is noted, it is paired with a word (a number name) and these words are named in a fixed order 'one, two, three...' (Resnick and Ford, 2012, p.69). As children develop a sense of number, they start to record their thoughts about quantity. There are various methods used to record numbers, perhaps the most common method being the use of fingers to represent numbers. Fingers are readily available, agile, discreet and present as the most obvious way to count (Andres, Ostry, Nicol, Paus, 2008; Di Luca and Pescenti, 2011). As Briggs (2013) points out, young children start to count as part of learning nursery songs. This is often heard as one continuous word (for example: 'onetwothreefourfive, once I caught a fish alive'). It is important to separate the words into their separate numbers. Simply because a child can sing the numbers in the correct order does not mean that they understand what the numbers mean, and that the numbers represent a number of objects.

Counting allows children to work out the quantity of any set. They do this by using number words to identify each item in a set. This involves certain important ideas, including the use and understanding of word numbers and sequence. Language represents a significant tool in the development of number sense. Children acquire verbal tools through the use of number words, allowing them to render their ideas about number explicit (Fosnot \& Dolk, 2001; Fuson, 2012; Fuson, Richards, \& Briars, 1982).

According to Gelman and Gallistel (1978), meaningful counting is far more complex than just speaking a string of counting words. Children must first understand five principles of counting if they are accurately to use counting to solve problems, make comparisons and quantify. The five principles of counting are:

a. stable order principle: the order of numbers is fixed. It is invariant.

b. One-one principle: One-to-one matching of number names to objects.

c. Cardinal principle: Connecting cardinal and ordinal aspects. Child has to discover that the ordinal number of the last object is the cardinal number of the set.

d. abstraction principle: Three sweets and four sweets, represent by the same abstraction $3+4=7$

e. order-irrelevance principle: children count a row of objects from left to right or from right to left make no difference.

Besides counting songs, the physical action of finger counting is done in a wide variety of ways: palm turned toward others, or towards oneself; counting starts with the right or left hand and with the index, thumb or little finger; switching between hands may be based on spatial continuation or anatomical symmetry (Menninger, 1969; Lindemann et al., 2011). Briggs (2013) points out that children keep track of counting in three different ways: 'touch counters; visual counters; physical partitions'. Visual counters 'point' with their eyes or head movements. Touch counters touch each item to be counted. Physical partitions move items as they count to ensure that they have counted each item in turn. Briggs (2013) describes what she calls 'extended counting' namely where the students can count up and down a number sequence so as to help them understand the concept of the bi-directional chain. Fuson (1992) 
also states that counting words can be produced fluently in either direction - they can count up or down the number sequence.

The above are understandings about counting for finding the quantity of a set. In the study the various counting strategies employed by the individual students were carefully observed, as were their skills in using such strategies. The study shows the importance of ensuring that students gain a wide variety of counting skills at as early a stage as possible. In particular, the study stresses the importance of teachers identifying what particular counting strategies their students are familiar with and how well they use them before moving on to presenting them with problems which require a good understanding of counting skills. In other words, it is vital to make sure that children 'can walk before they can run'.

\section{METHOLOGY}

\section{Participants}

The 27 students in the study all attended the same school and were aged seven to nine years old. The students were individually interviewed with the tasks shown in table one. These tasks were designed to reveal how they approached the problems, what difficulties they encountered and why they encountered. All interviews were video-recorded and observations were made of the children's' actions, behaviour, verbalization, interaction with each other and their thinking processes

\section{Interview procedure}

The problem was read to the students and they were provided with a pencil and paper to solve the problem. If a child appeared not to understand the question, then it would be rephrased. If the child suggested an incorrect solution, then the question would be rephrased - either by changing the words of the question, or by the changing the quantities in the question to make it simpler.

Changing the words: 'You have two dollars and your mummy gives you an extra three dollars, how many do you have altogether?' might be rephrased as, 'You have two dollars and your mummy gives you an extra three dollars. If you put them together, how many do you have?'

Changing the numbers: 'You have nine dollars and your mummy gives you five dollars, how many do you now have?' might be changed to, 'You have five dollars and your mummy gives you four dollars, how many do you have altogether?' When changing the numbers one addend might be kept unchanged (for example, ' $5+9$ ' might be changed to ' $5+4$ '). Alternatively, both addends might be changed (e.g. ' $3+6$ ').

After the verbal presentation, observations were made of how the children used the information. For example, if they wrote a number sentence or used concrete items to solve the problem. If it appeared that the children had not understood the question, then they would be supplied with something to help them such as concrete material. For example, if a child was having difficulty with ' $2+7$ ' they might be given two coins but, if they were still struggling, they would be given a further seven coins. They would then be observed to see how they would use those coins and/or pencil and paper to find the answer. They would not be given the two coins and seven coins together, since all they would then have to do was to count them all. 


\section{Global Conference on Education \& Teaching}

\begin{tabular}{|c|c|c|}
\hline & The Addition Problems set & Explanation \\
\hline $2+7$ & $\begin{array}{l}\text { small number + large number (number } \\
\text { greater than 5) }\end{array}$ & $\begin{array}{l}\text { To see whether they could adopt } \\
\text { the strategy of starting with the } \\
\text { larger number and use the } \\
\text { commutative property of } \\
\text { addition to reverse the number } \\
\text { to make it easier to find the } \\
\text { solution. }\end{array}$ \\
\hline $5+4$ & $\begin{array}{l}\text { two numbers, quantity close together, } \\
\text { each number can be counted on one } \\
\text { hand }\end{array}$ & $\begin{array}{l}\text { These would be easier for the } \\
\text { children to solve using their two } \\
\text { hands. It might be easier for } \\
\text { them to subitise. }\end{array}$ \\
\hline $9+5$ & $\begin{array}{l}\text { greater number than can be counted on } \\
\text { one hand }+ \text { smaller number which can } \\
\text { be counted on one hand }\end{array}$ & $\begin{array}{l}\text { To see how children would } \\
\text { tackle them when the total } \\
\text { number exceeding the number } \\
\text { of fingers. This was based upon } \\
\text { the common way of counting - } \\
\text { each finger representing one } \\
\text { number. }\end{array}$ \\
\hline $8+7$ & $\begin{array}{l}\text { Two numbers, each number is a greater } \\
\text { number than can be counted on one } \\
\text { hand }\end{array}$ & $\begin{array}{l}\text { This would mean a greater } \\
\text { number than the fingers on their } \\
\text { hands, to see whether they were } \\
\text { still able to use finger-counting } \\
\text { strategies, or what alternative } \\
\text { strategies, if any, they might } \\
\text { adopt. }\end{array}$ \\
\hline
\end{tabular}

\section{Table 1. Different number combinations tasks}

\section{Analysis}

A grounded (Strauss and Corbin, 1990) analysis was used where observations were made of the types of solution strategies that the students employed and codes related to these were developed. The codes are shown on Figure 1 below. It was observed that the students employed a variety of strategies.

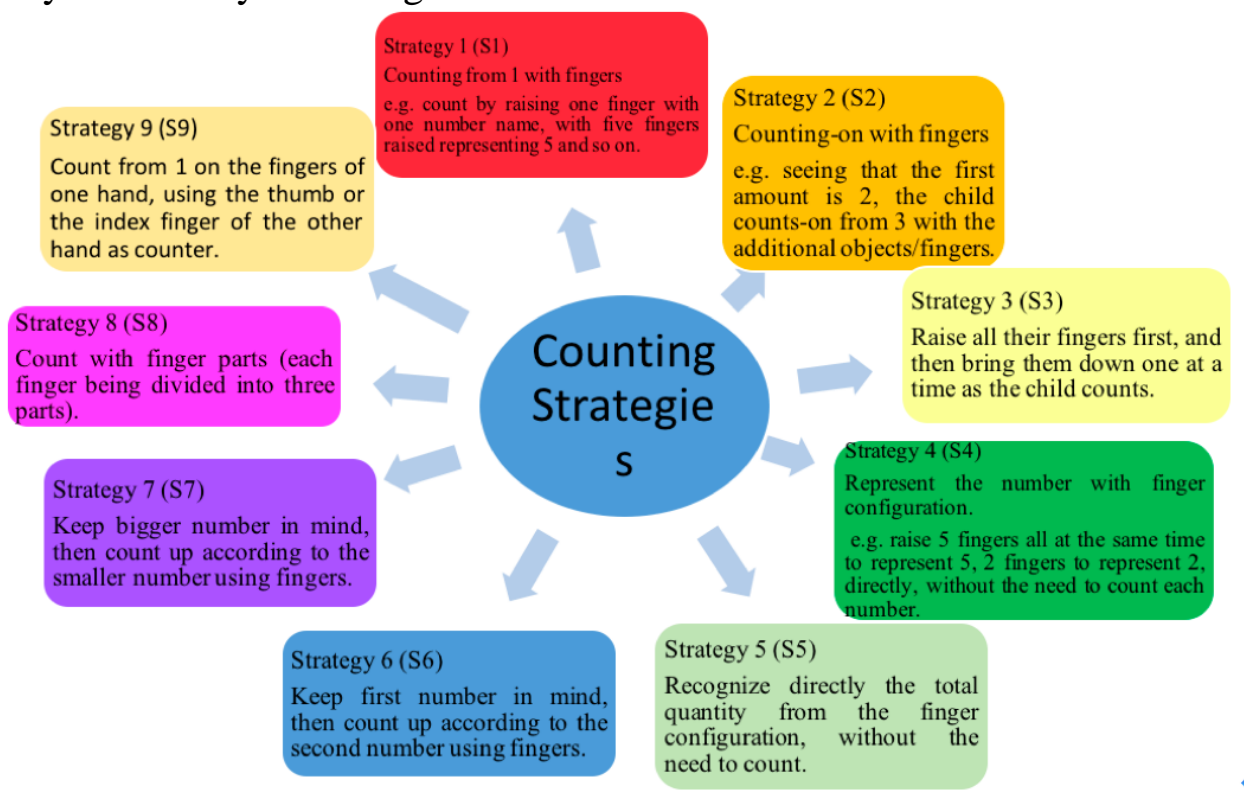

Figure 1. Counting Strategies 


\section{FINDINGS AND DISCUSSION}

The findings highlight the range of strategies employed by the students.

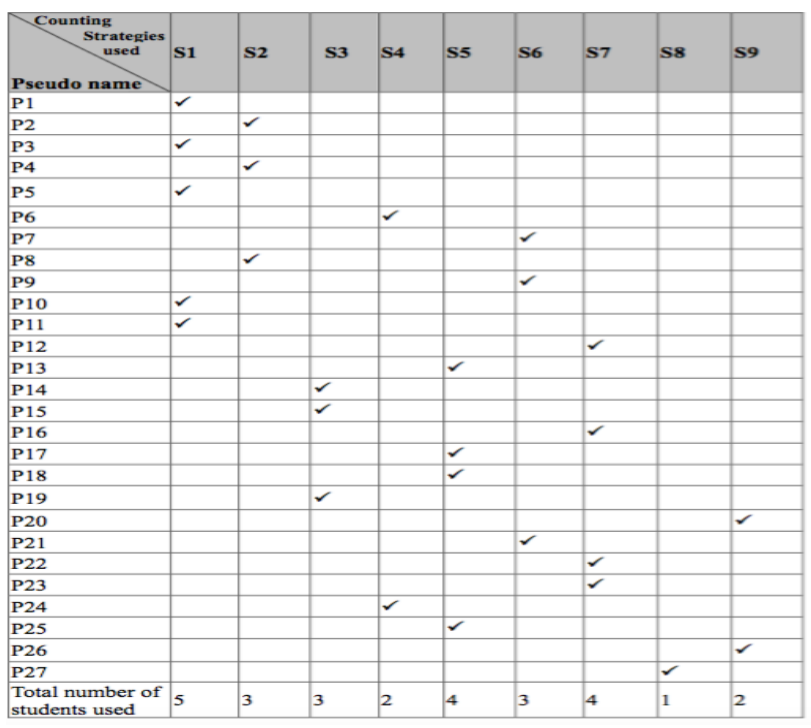

\section{Table 2. Students' counting strategies in handling Simple Mathematics Problems}

\section{Subitising}

Subtising is recognising how many things there are without having to count them individually. Thus, a student seeing four raised fingers might be able immediately to recognise that there are four without having to count them. But subitising works the other way round also: if a student is asked 'show me four fingers' and they immediately raise four fingers (without having to count), that is subitising. Subitising is helpful in simple addition word problems because the child can immediately start by subitising one or other addend and then work from there, as Strategies 4 and 5. Perhaps it might be by using counting on or some other strategy. Subitising speeds up the process. In the study, very few of the students demonstrated any subitising skills. They had to rely on their other counting strategies and this, undoubtedly, made the problem-solving process much slower and more difficult. This leads to one of the reasons of why students were unsuccessful.

\section{Counting strategies}

The study shows how few counting strategies the students used; it also showed that very few were skilled at using the strategies they did know.

As can be seen from the table 2, the study identified nine counting strategies, but not all children used all nine strategies. Only a small number counted using finger parts (see Strategy 8). It might be thought of as a very efficient method of counting using fingers since it provides children with a total of 15 'counts' per hand, yet so few used this method and, of those that did, many became confused because they were not able to count up to 15 .

The most common method of counting was Strategy 1, but this is an inefficient way of counting because the children would always start from 1 and, when they got to 10, but needed to go higher, they couldn't because they had simply run out of fingers. 
The vast majority of students used only one method of counting and, whatever method of counting they used, many made mistakes. One would have expected each student to have possessed and used a wide range of counting skills, and to have use them effectively, but this was not the case.

\section{CONCLUSION}

In this qualitative research, the number of students involved in the study was relatively small (27), but they were observed over a prolonged period for many hours. Each child was interviewed, and the interviews videoed. The videos were studied at length. The lack of variety of counting strategies, and lack of skill in using those strategies underscores the importance of teachers, themselves, being aware of the variety of counting methods available, teaching a variety of counting skills and making sure that the students understand them, know how to use them efficiently, and which strategy works best in which situation.

It seems significant that, even though the students were all from the same school, they did not seem to adopt standard strategies. Although one would expect children to select the strategy which was the most useful for them, nonetheless, one would have expected these children to have displayed a knowledge of several counting strategies and to have switched between them to find the most efficient method of solving the problem, but they did not. The paucity of strategies, and the difficulties these children displayed represented a real hindrance to their progress in the learning of mathematics.

Well-designed teaching games are an effective teaching form. In order to realize the expected educational aims, teachers should make a sufficient preparation. The study highlights the need for teachers to be alert to the strategies their students are using and how well they use them. This is especially the case where their students are performing badly in mathematics going back to fundamentals could well help teachers identify the reason for poor performance so that they can then take remedial action. It is hoped that the method used in the study (identifying the reasons for poor performance in the subject school) can be applied by teachers in other schools, wherever they might be.

\section{References}

Andres, M., Ostry, D. J., Nicol, F., \& Paus, T. (2008). Time course of number magnitude interference during grasping. 44, 414-419.

Briggs, M. (2013). Teaching and Learning Early Years Mathematics: Subject and Pedagogic Knowledge. Plymouth: Critical.

Counting and young children. (n.d.). Retrieved from http://earlymathlearning.com/PDFs/7CountingAndYoungChildren.pdf

Di Luca, S., \& Pesenti, M. (2011). Finger numeral representations: more than just another symbolic code. Frontiers in Psychology, 2, 1-3.

Fosnot, C. \& Dolk, M. (2001). Young mathematicians at work: Constructing number sense, addition and subtraction. Portsmouth, NH: Heinemann.

Fuson, K. C., Richards, J., \& Briars, D. J. (1982). The acquisition and elaboration of the number word sequence. In C. Brainerd (Ed.), Progress in cognitive development 


\section{Global Conference on Education \& Teaching}

25-27 June , 2021

Vienna, Austria

research: Children's logical and mathematical cognition (Vol. I, pp. 33-92).New York, NY: Springer-Verlag.

Fuson, K. C. (2012). Children's counting and concepts of number. New York, NY: SpringerVerlag

Fuson, K. C. (1992). Research on whole number addition and subtraction. In D. A. Grouws (Eds.), Handbook of research on mathematics teaching and learning. New York: Macmillan.

Gelman, R., \& Gallistel, C. (1978). The Child's Understanding of Number. Cambridge, MA: Harvard University Press.

Gibbons, L \& Lomax, K. (2015, November 23). Counting: Why is it Important and How Do

We Support Children? Retrieved from

http://www.nctm.org/Publications/Teaching-Children-Mathematics/Blog/Counting_Why-is-it-Important-and-How-Do-We-Support-Children_-Part-1/

Kilpatrick, J., Swafford, J. \& Findell,B. (2001). Adding It Up. Mathematics Learning Study Committee, Center for Education, Washington, DC: National Academies Press.

Lindemann, O., Alipour, A., \& Fischer, M. H. (2011). Finger counting habits in middleeastern and western individuals: an online survey. J. Cross Cult. Psychol, 42, 566-578.

Menninger, K. (1969). Number Words and Number Symbols. Cambridge: MIT Press.

Neuman, D. (1987). The origin of arithmetic skills: A phenomenographic approach.

Göteborg: Acta Universitatis Gothoburgensis.

Resnick, L. B., \& Ford, W. W. (2012). The psychology of mathematics for instruction (pp.69). Hillsdale, NJ: Erlbaum.

Rogers, Carl R. (1969). Freedom to Learn: A View of What Education Might Become. Columbus, Ohio: Charles E. Merrill Publishing Company.

Strauss, A. \& Corbin, J. (1990). Basics of Qualitative Research: Grounded Theory Procedures and Techniques. Newbury Park, CA: Sage Publications. 